\title{
Scanning Micrographic Views of Odontoblasts of Dog Teeth
}

\author{
by \\ Atsushi TOMITA, * Michio KABAZAWA, ${ }^{*}$ Toshiyuki KODAMA, * \\ Yoshito IWATAKE,* Michinori KATAGAMI* and Takeo KIZU*
}

\section{Introduction}

IsOKAWA et al. [1] and YAMAKAWA [2] studied the predentinal surface of human teeth by use of the scanning electron microscope and respectively published somewhat insufficient descriptions of odontoblasts seen there. KoDAma [3], one of the present authors, investigated the predentinal surface of dog teeth by the same technique and also described the odontoblasts, though only superficially.

As a further effort at the elucidation of odontoblasts of dog teeth, the present report deals with the morphology of dog odontoblasts.

\section{Material and Method}

For the collection of teeth samples for study, young adult dogs weighing about $10 \mathrm{Kg}$ were selectively used. After the teeth had been removed from jaw bones, each was cut into two to several pieces by a chisel. Under the stereoscopic microscope, pulp tissues were separated from these tooth pieces by pincettes, though insufficiently. Subsequently, the material was fixed by a $10 \%$ solution of neutral formalin and after dehydration by alcohol and acetone, it was subjected to scanning electron miscroscopy for observation of the predentinal surface.

\section{Findings}

As a result of scanning electron microscopy, it was possible to observe dog odontoblast lateral process, terminal bar and those fibers which resembled von Korff's fibers. Odontoblasts are seen to be closely arranged singly along the predentin which appears to be dark tone (Fig. 1). They are shaped like slender rods, 20 to $30 \mu$ in length, and have terminal bars on predentin side, and send the cytoplasmic processes of odontoblast to dentinal tubules. The diameter of dentinal tubules appears to be larger in predentin than in calcified dentin.

A more detailed view of odontoblast and predentinal surface is possible (Fig. 2). Here, an odontoblast appears to be somewhat flat and one odontoblast gives an impression of being syncytially connected with adjacent odontoblasts by numerous lateral

* 富田篤, 椛沢道男, 児玉俊之, 岩武義人, 片上道範, 木津建夫, Department of Anatomy, Nihon University School of Dentistry, Tokyo (Director: Prof. Sohiti Isokawa). 


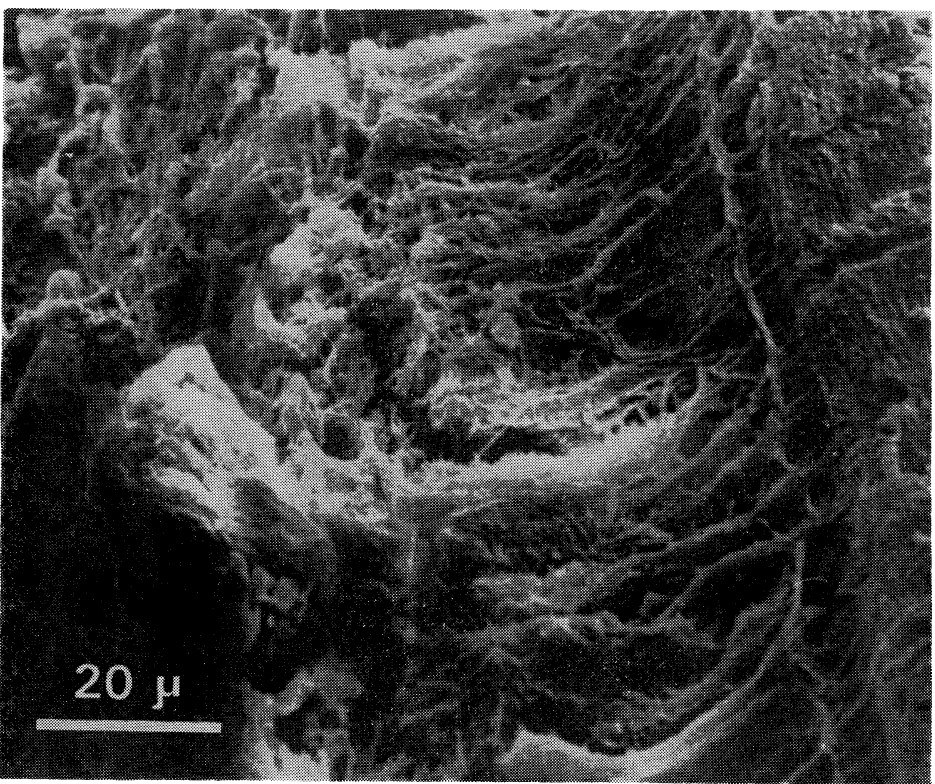

Fig. 1 Scanning microphotograph of pulpopredentinal area.

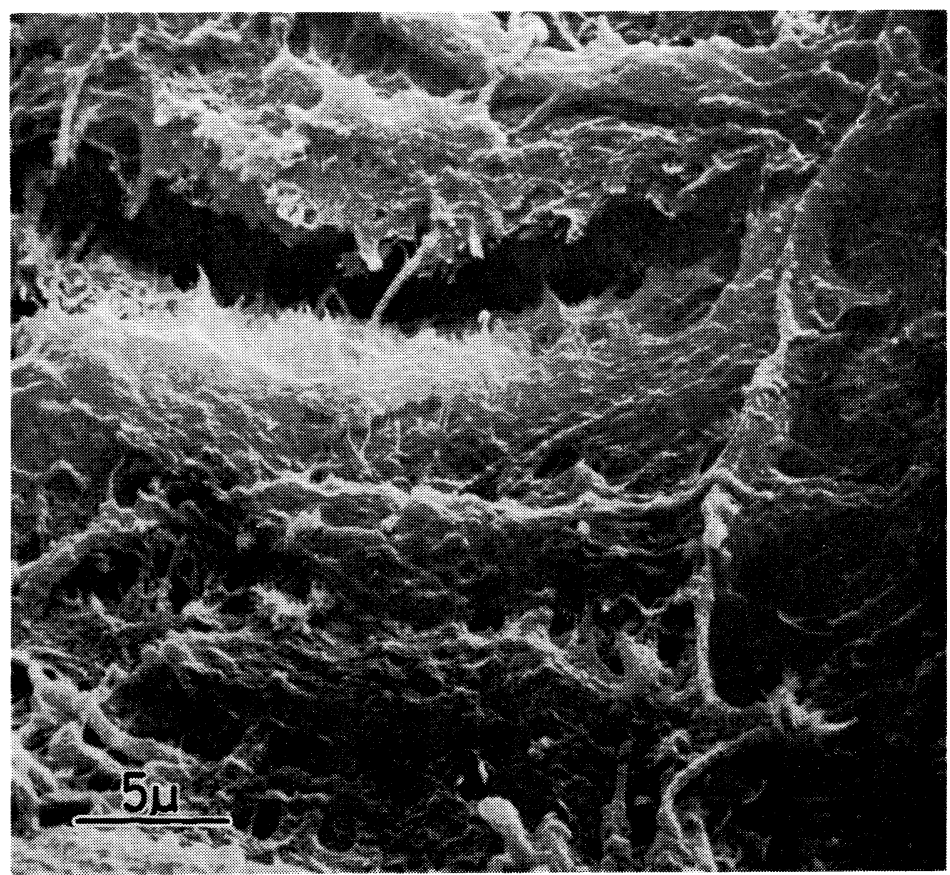

Fig. 2 Higher magnification of odontoblasts. One can see many lateral processes and membranous terminal bars. 


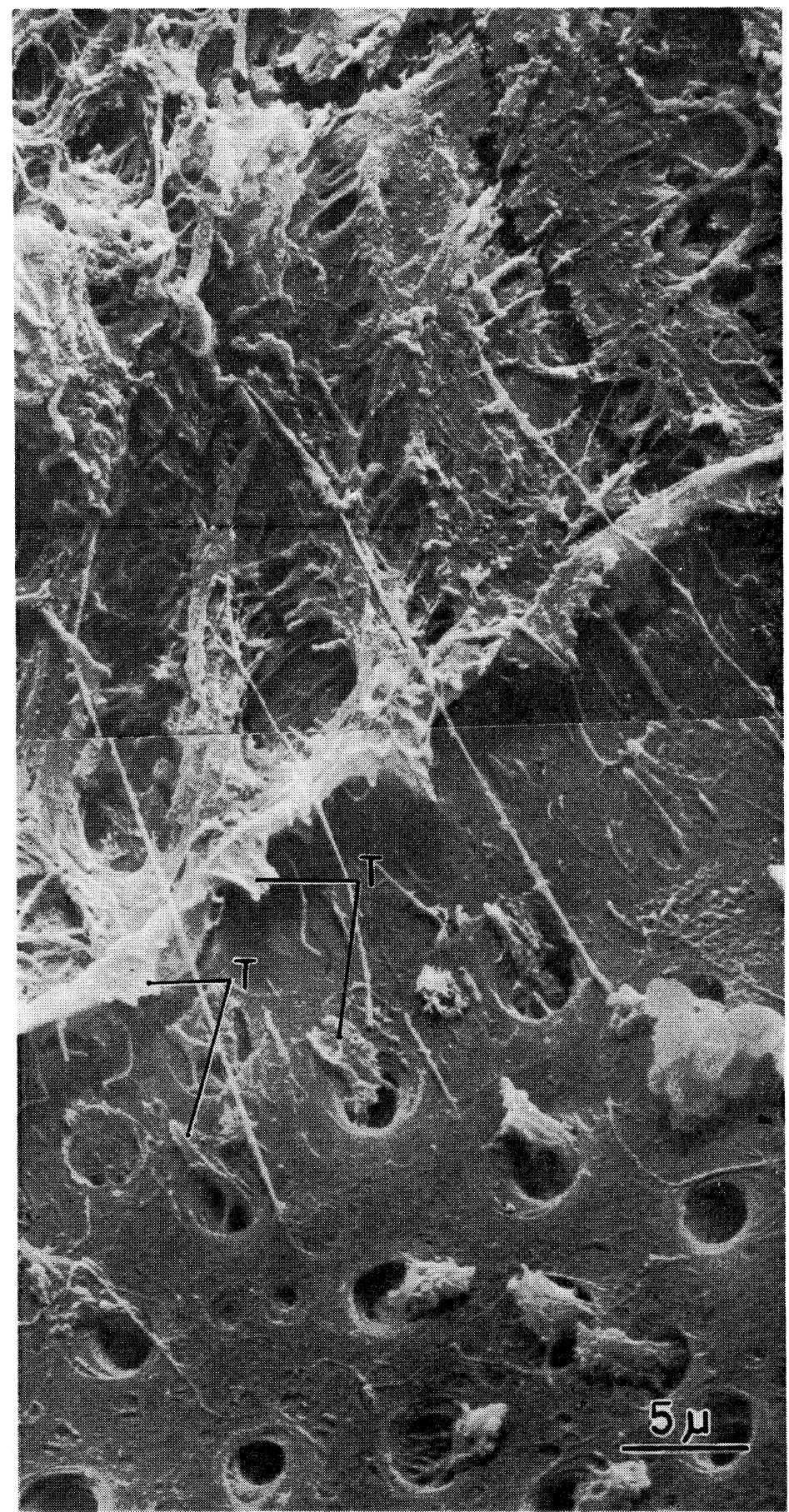

Fig. 3 Predentinal surface of dog tooth. It shows odontoblasts and their cytoplasmic processes $(\mathrm{T})$ occupied in dentinal tubules. 
processes. However, a little intercellular space is observable there. At the odontoblast predentin junction, a terminal bar which appears as if a membrane is present. Part of this terminal bar is observed as if to embrace the cytoplasmic processes (Tomes' fibers) of odontoblasts that extend themselves toward dentinal tubules of predentin.

Some of the cytoplasmic process of odontoblasts was torn off in the process of specimen preparation and one torn portion appears as a short conical prominence from a terminal bar. The other torn portion occupies a dentinal tubule lumen of predentinal surface (Fig. 3, T).

With predentinal surface, its matrix fibrous network cannot be observed clearly enough. However, it is possible to discern some fibers which go from dental pulp proper to predentinal surface by way of odontoblasts. These fibers, much finer than the cytoplasmic process of odontoblasts, participate in the formation of network as predentin matrix fibers.

\section{Discussion and Conclusion}

In the present study, main attention was focused on the lateral process of odontoblasts, terminal bar and fibers that connect pulp and predentin surface.

As mentioned in the foregoing section, earlier efforts of IsoKAwA et al. [1] and YAMAKAWA [2] failed in their observations of the lateral process of odontoblasts when they had studied them by means of scanning electron microscopy. This time, it was made clear that odontoblasts are syncytially connected by lateral processes. The presence of terminal bar at the junction of odontoblast and predentin is attested even by the light microscope and, here, the authors tried to studey it scanning micrographically.

As a result, terminal bar appears to be membranous and part of it look as if to embrace the cytoplasmic process of odontoblasts. However, within the scope of this study it has not been possible to identify this membranous structure with membranous structure inside dentinal tubules respectively reported by JOHANSEN [4], BRÄNNSTRÖM and GARBEROGLIO [5], and IsOKAWA et al. [6].

A fibrous system connecting pulp and predentin was seen and, from its construction, this is thought to be one of fibers that make up dentin matrix. However, it cannot be definitely established whether they correspond to the so-called Korff's fibers earlier described by IsOKAWA et al [7] and KoDAma [3], though this possibility is open.

\section{References}

[1] Isokawa, S., Toda, Y., Kodama, N. and Inoue, Y.: Scanning electron microscopy of human odontoblasts and predentin, J. Nihon Univ. Sch. Dent., 12, 54 56, (1970).

[2] Yamakawa, H.: A scanning electron microscopic study of the predentinal surface of human tooth dentin, Nihon Univ. dent. J., 47, 57-62, (1973) (Japanese).

[3] Kodama, T.: A scanning electron microscopic observation of the predentinal surface of dog tooth, Nihon Univ. dent J., 47, No. 2, (Japanese) (in press).

[4] JohANSEN, E.: Ultrastructure of dentine. (Structural and chemical organization of teeth, edited by A. E. W. Miles.) Acad. Press, New York and London, Vol. II, 35 74, (1967).

[5] Brännström, M. and Garberoglio, R.: The dentinal tubules and the odontoblast processes. A scanning electron microscopic study, Acta odont. scand., 30, 291 311, (1972).

[6] Isokawa, S., KuвотA, K. and Shimauchi, K.: Membranous structure in the human dentinal 
tubules. A scanning electron microscopic observation, 127th meeting of Nihon Univ. Sch. Dent., Feb. (1972).

[7] Isokawa, S., Uchino, S., Mormoto, K., Kobayashi, Y. and Hasegawa, S.: On the so-called von Korff's fibers as seen on the human predentinal surface, J. Nihon Univ. Sch. Dent., 14, $12 \sim 15$, (1972). 